\title{
Underground Wireless Sensor Network Communication Using Electromagnetic Waves Resonates at $2.5 \mathrm{GHz}$
}

\author{
Abde Irahman Elle ithy ${ }^{*}$, Gons hin Liu, Ali Elrashidi \\ Department of Computer Science and En gineering, University of Bridgeport, Bridgep ort, CT 06604, USA
}

\begin{abstract}
A comprehensive study of electromagnetic waves underground propagation for a wireless sensor network is introduced in this paper. A mathematical model for path loss due to attenuation of electromagnetic waves propagating in different types of soil is given. Reflection from the air-soil interface as a function of distance between sensors and soil depth is also introduced. Three different types of soil, sandy, loamy and magnetite soil are studied. A high gain antenna is required to overcome the high value of path loss. A printed mic rostrip circular antenna is very common antenna used for underground wireless communication applications. A high gain microstrip circular antenna is designed and simulated using FEKO software. The antenna performance parameters studied in this paper are return loss, voltage standing wave ratio, input impedance and gain.
\end{abstract}

Keywords Wireless Sensor Network, Electromagnetic Waves, Reflection, Microstrip Circular Antenna, FEKO Software, Voltage Standing Wave Ratio (VSW R), Input Impedance, Retutn Loss (S11), Antenna Gain

\section{Introduction}

A wire less sensor network (WSN) consists of sensors used to monitor physical or environmental phenomena such as humid ity, temperature, sound, vibration, pressure or motion and cooperatively pass the data through the network of sensors to a main location[1]. As wireless network sensors become smaller in dimension and cheaper, researchers are deploying them in environments that are unconventional for electromagnetic signaling[2]. One of those applications for wireless sensor network is underground wireless communication to monitor soil properties and then transmit the collected data to a node on the surface[3]-[8].

Wireless underground sensor network has a lot of applications including: environmental monitoring, infrastructure monitoring, location determination and border patrol and security monitoring $[9,10]$.

Wireless communication using electromagnetic signals suffers fromhigh attenuation in soil, due to the absorption of the signal. So, the underground wire less communication can be characterized by high signal loss due to absorption and multi-path losses caused by soil molecules such as reflection and refraction[11]. The main advantages of using electromagnetic waves instead of sound are: first, electromagnetic waves reduce the latency due to faster propagation. Second, electro magnetic waves give a high data

* Corresponding author:

aelleith@bridgeport.edu (Abdelrahm an Elleithy)

Published online at http://journal.sapub.org/jwnc

Copyright (C) 2012 Scientific \& Academic Publishing. All Rights Reserved rate due to high frequency of the wave[12].

In this paper we discuss the propagation of electromagnetic waves in sandy soil, loamy soil and magnetite soil and study the effect of changing distance between the sensors and change the operating frequency, 2.5 $\mathrm{GHz}$ range[13]. The designed microstrip circular antenna with a high gain to overcome the path loss due to attenuation in the soil is also introduced in this paper.

\section{Related Work}

There has been some work focusing on electromagnetic waves propagation through soil and water. N. Channmwe at al. introduced the empirical attenuation and relative permittivity values for different materials including soil at 300-700 MHz frequency range[14]. Reflection and refraction from the underground-air interface are also introduced in this paper. The path loss due to material absorption in underground propagation is presented by $\mathrm{N}$. Peplinski. Path loss as a function of volumetric water content $5 \%, 10 \%, 15 \%, 20 \%$ and $25 \%$ for a frequency range $1.3-3$ $\mathrm{GHz}$ is introduced in this paper[15].

A bit error rate and path loss as a function in frequency and sensor depth for different volumetric water content are introduced by I. Akyildiz at el.[16]. There are several challenges in the design of wireless underground communication network such as network topology, reliability, localization and network architecture design.

The communication through soil is represented as an electromagnetic wave transfer through the transmission line by T. Weldon and A. Rathore[17]. The operating frequency 
range is $1-2 \mathrm{GHz} . \operatorname{In}[18]$, the authors show that the soil composition has significant effects on the ground penetrating radar.

\section{Effect of Soil Properties on Underground Communication}

The soil properties have a great effect on the underground communication using electromagnetic waves. Dielectric constant is most important parameter that affects the propagation in underground communication. Water content, density, particle size and temperature are also affecting the communication.

\subsection{Water Content}

Signal loss through a given type of soil is depending on water concentration in soil. Increasing the water content of a soil makes the channel more power loss. As water content raise from dry the $13 \%$ volumetric, the losses per meter increased by $137 \mathrm{~dB}$ at $1 \mathrm{GHz}$ frequency[17].

\subsection{Density}

The path loss increases as the soil density is increasing. Also, the signal attenuation increases with increasing the soil density.

\subsection{Particle Size}

There are three different types of soils according to particle size. Three major components are given in[18] as sand, silt and clay. Sandy soil is the smallest particle in size and gives a lower losses and clay soil gives the highest losses for its large particle size[19].

\subsection{Temperature}

Dielectric properties are function of temperature, so the increasing in temperature leads to increase the signal attenuation in underground communication.

\section{Antenna Background}

Underground communication needs a very efficient antenna for wireless sensor network communication. This antenna must meet a number of requirements for underground communication to overcome the high value of path loss due. This kind of antenna must has a high gain, above $10 \mathrm{~dB}$, and should be small in dimension so that it can be fitted on the sensor surfaces. The most common antenna used for underground communication using electro magnetic signals is circular microstrip antenna[2].

\subsection{Background}

A circular microstrip antenna is a popular for frequency range for Ultra High Frequency (UHF), fro $300 \mathrm{MHz}$ to 3 $\mathrm{GHz}$, up to the millimeter wave range, from $30 \mathrm{GHz}$ to 300 $\mathrm{GHz}$, and has also found application in arrays. The circular antenna performance is not sensitive to small parameter variations, improving robustness to manufacturing tolerances. While the circular microstrip antenna provides reasonable wide-band performance, this is not a high performance antenna[20, 21].

\subsection{Physical Description}

The circular microstrip antenna is easy to construct and can be very robust, but can become restrictively large at low frequencies. This antenna is an electrically large antenna with a one wavelength circumference. The ga in is stable over a substantial band; however, the input impedance shows a large variation[22, 23].

\section{Underground Signal Propagation}

The signal propagation in soil depends on the path loss in soil. Received power as a function of transmitted signal, path loss and antenna gain at the receiver end is given from Friis equation as shown in Equation 1[24].

$$
\begin{aligned}
& P_{\text {rec }}(d B m) \\
= & P_{i}(d B m)+G_{t}(d B)+G_{r}(d B)-L_{\text {pat hloss }}(d B)(1)
\end{aligned}
$$

where $P_{t}$ is the transmit power, $G_{r}$ and $G_{t}$ are the gains of the receiver and transmitter antenna, $L_{\text {Pathloss }}$ is the path loss in soil.

The path loss is shown in Equation 2[25].

$$
L_{\text {pat hloss }}(d B)=L_{0}(d B)+L_{w}(d B)+L_{\text {att }}(d B)
$$

$L_{0}$ is the path loss in air and given by:

$$
L_{0}(d B)=20 \log \left(\frac{4 \pi d f}{c}\right)
$$

where $d$ is the distance between transmitter and receiver in meter, $f$ is the operating frequency in Hertz and $c$ is the velocity of light in air in meter per second.

$L_{w}(d B)$ is the path loss due to changing in medium and given by[26]:

$$
L_{w}(d B)=20 \log \left(\frac{\lambda_{0}}{\lambda}\right)
$$

where $\lambda_{0}$ is the signal wavelength in air and calculated $\left(\lambda_{0}=c / f\right)$ and $\lambda$ is the wave factor and given by $(\lambda=2 \pi / \beta)$ and $\beta$ is the phase shifting constant and calculated as shown in Equation 5.

$$
\beta=\omega \sqrt{\frac{\mu \varepsilon^{\prime}}{2}\left(\sqrt{1+\left(\frac{\varepsilon^{\prime \prime}}{\varepsilon}\right)^{2}}+1\right)}
$$

where $\varepsilon$ and $\varepsilon$ are the real and imaginary parts of the complex dielectric constant given by $\left(\varepsilon=\varepsilon^{\prime}-j \varepsilon^{\prime \prime}\right)$.

$L_{a t t}(d B)$ is the path loss due to attenuation in medium and given by:

$$
L_{a t t}(d B)=10 \log \left(e^{-2 \alpha d}\right)
$$

where $\alpha$ is the attenuation constant and calculated as shown in Equation 7:

$$
\alpha=\omega \sqrt{\frac{\mu \varepsilon^{\prime}}{2}\left(\sqrt{1+\left(\frac{\varepsilon}{\varepsilon}\right)^{\prime \prime}}-1\right)}
$$




\section{Reflection from Ground Interfaces}

The reflection from the surface and bottom depends on reflection coefficient at the interface between soil and air. The reflection coefficient is given by Equation 8[27].

$$
\Gamma=\frac{\rho_{2} v_{2}-\rho_{1} v_{1}}{\rho_{2} v_{2}+\rho_{1} v_{1}}
$$

where $\rho_{1}$ and $\rho_{2}$ are the density of the first and second medium respectively and $v_{1}$ and $v_{2}$ are the wave velocity in both mediums.

The reflection loss fro $m$ the surface and fro $m$ the bottom is $L_{r e f}$ and shown in Equation 9.

$$
L_{r e f}=-V(d B)=-10 \log (V)
$$

where is calculated as shown below:

$$
\begin{gathered}
V^{2}=1+\left(|\Gamma| e^{-\alpha \Delta(r)}\right)^{2}-2|\Gamma| e^{-\alpha \Delta(r)} \times \cos (\pi-(\phi- \\
\left.\left.\frac{2 \pi}{\lambda} \Delta(r)\right)\right)
\end{gathered}
$$

where $r$ is the reflected path length, $|\Gamma|$ and $\phi$ are the amp litude and phase of the reflection coeffic ient respectively and $\Delta(r)$ is the difference between $r$ and $d$.

where $r$ can be calculated as follow:

$$
r=2 \sqrt{H^{2}+\left(\frac{d}{2}\right)^{2}}
$$

Figure 1. illustrates the three-path channel model, including reflection from the air and soil interface and from the sand.

where $d$ is the distance between two sensors, $H$ is the distance between surface and the sensor and $r$ is the distance between the sensor and the reflection point.

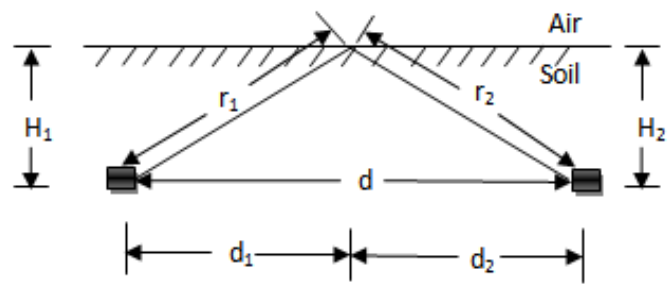

Figure 1. Two-path channel model
Table 1. Dielectric constant and tangent loss for different soil types[13]

\begin{tabular}{|c|c|c|c|}
\hline No. & Soil-Water ratio & $\begin{array}{c}\text { Dielectric } \\
\text { constant } \varepsilon_{\mathrm{r}}\end{array}$ & $\begin{array}{c}\text { Tangent } \\
\text { loss tan }(\delta)\end{array}$ \\
\hline 1 & Sandy-Soil Dry & 2.55 & 0.0062 \\
\hline 2 & Sandy-Soil 3.88\% water & 4.4 & 0.046 \\
\hline 3 & Sandy-Soil 18.8\% water & 20 & 0.13 \\
\hline 4 & Loamy-Soil Dry & 2.44 & 0.0011 \\
\hline 5 & Loamy-Soil 2.2\% water & 3.5 & 0.04 \\
\hline 6 & Loamy-Soil 13.77\% water & 20 & 0.12 \\
\hline 7 & Magnetite-Soil Dry & 1.05 & 0.029 \\
\hline 8 & Magnet ite-Soil 4.8\% water & 8.3 & 0.22 \\
\hline 9 & Magnetite-Soil 11\% water & 30 & 0.32 \\
\hline
\end{tabular}

\section{Results}

The effect of frequency on the path loss for different values of distance between sensors using different soil types is illustrated in the following sections. Nine different soil types are shown in Table 1 according to the water concentration in soil.

\subsection{Path Loss Calculation}

The total path loss due to communication between sensors without reflection loss is shown in the next sections.

\subsubsection{Sandy Soil}

The sandy soil is the normal pure soil. The Particle density, which is the weight per unit volume of the solid portion of soil, of normal soils is $2.65 \mathrm{~g} / \mathrm{cm} 3$. The Bulk density, the oven dry weight of a unit volume of soil inclusive of pore spaces, of a soil is always smaller than its particle density and is about $1.6 \mathrm{~g} / \mathrm{cm}^{3}$ and the pore space is $40 \%$ [28].

The sandy soils with three different concentration of water are studied in this section. The path loss for the dry sand soil with relative permittivity $\varepsilon=2.55$ and tangent loss is $\tan (\delta)=0.0062$, sandy soil $3.88 \%$ water with $\varepsilon^{`}=4.4$ and $\tan (\delta)=0.046$ and sandy soil $18.8 \%$ water with $\varepsilon=20$ and $\tan (\delta)=0.13$ at $2.5 \mathrm{GHz}$ are given.

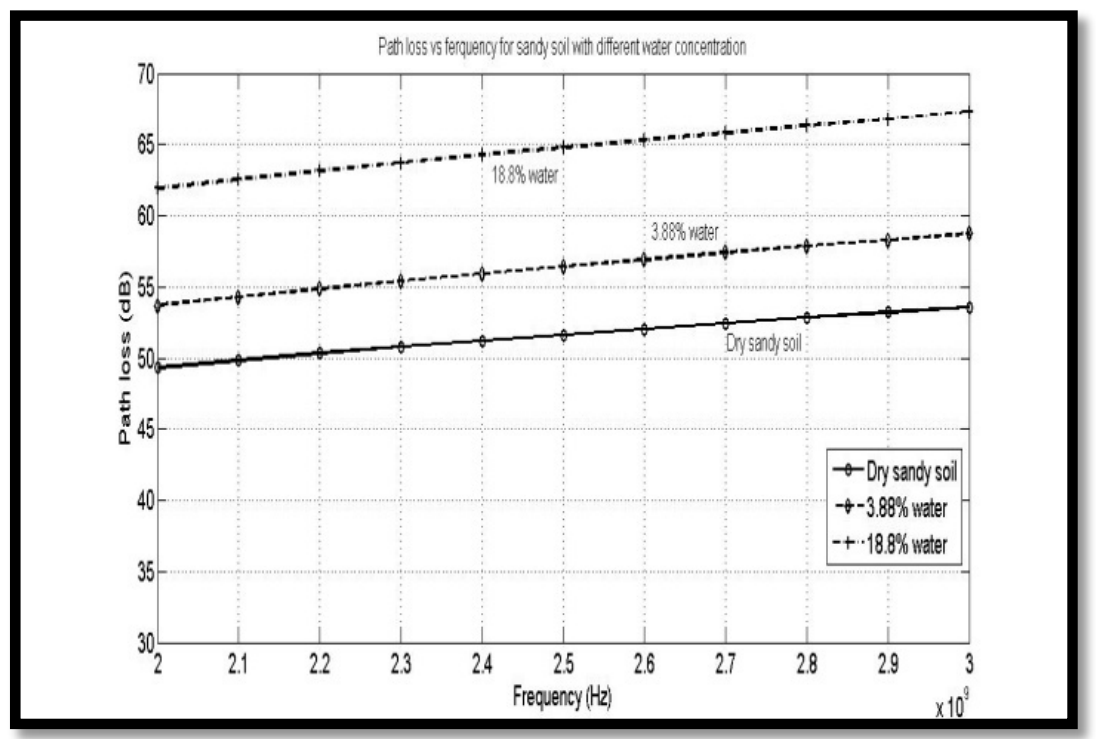

Figure 2. Path loss $(\mathrm{dB})$ as a function of frequency $(\mathrm{GHz})$ for sandy soil at different water concentration at distance $1 \mathrm{~m}$ 


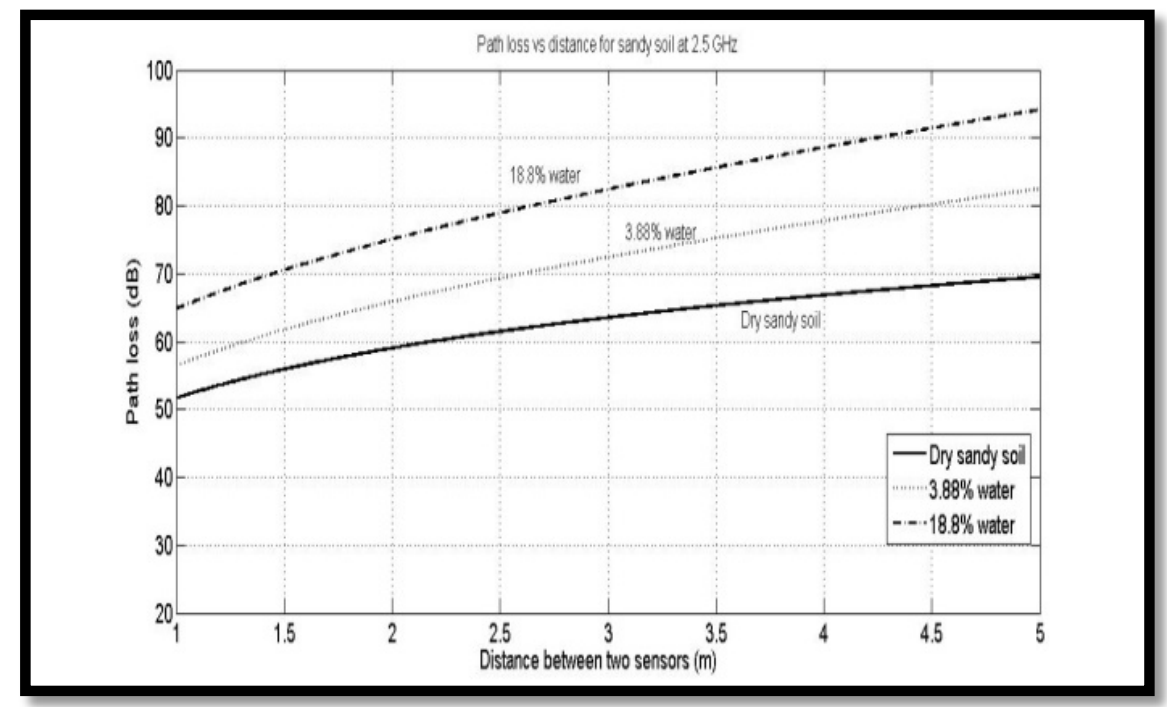

Figure 3. Path loss $(\mathrm{dB})$ as a function of distance between two sensors $(\mathrm{m})$ at frequency $2.5 \mathrm{GHz}$ for sandy soil at different water concentration

The effect of frequency on the path loss at distance between two sensors $1 \mathrm{~m}$ is illustrated in Figure 2. As clearly shown in the figure, as the frequency increases the path loss is also increases. The path loss is increased as the water concentration is increased due to increasing in the dielectric constant of the sandy soil. In Figure 3, the effect of distance on a path loss is illustrated for different values of water concentration at frequency $2.5 \mathrm{GHz}$.

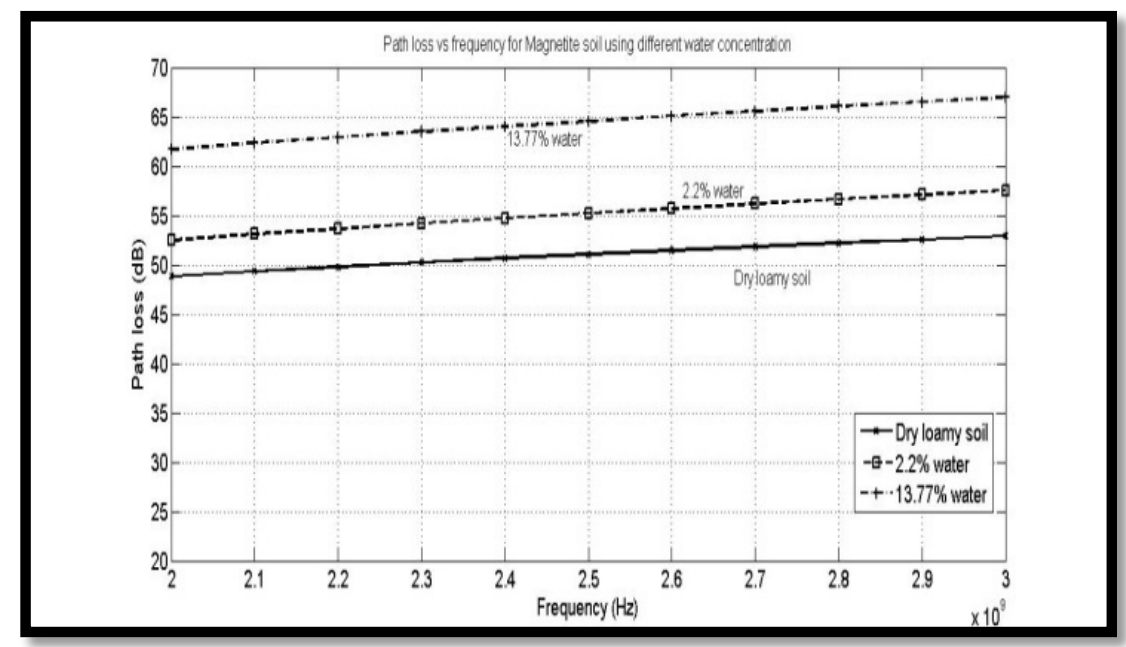

Figure 4. Path loss $(\mathrm{dB})$ as a function of frequency $(\mathrm{GHz})$ for loamy soil at different water concentration at distance $1 \mathrm{~m}$

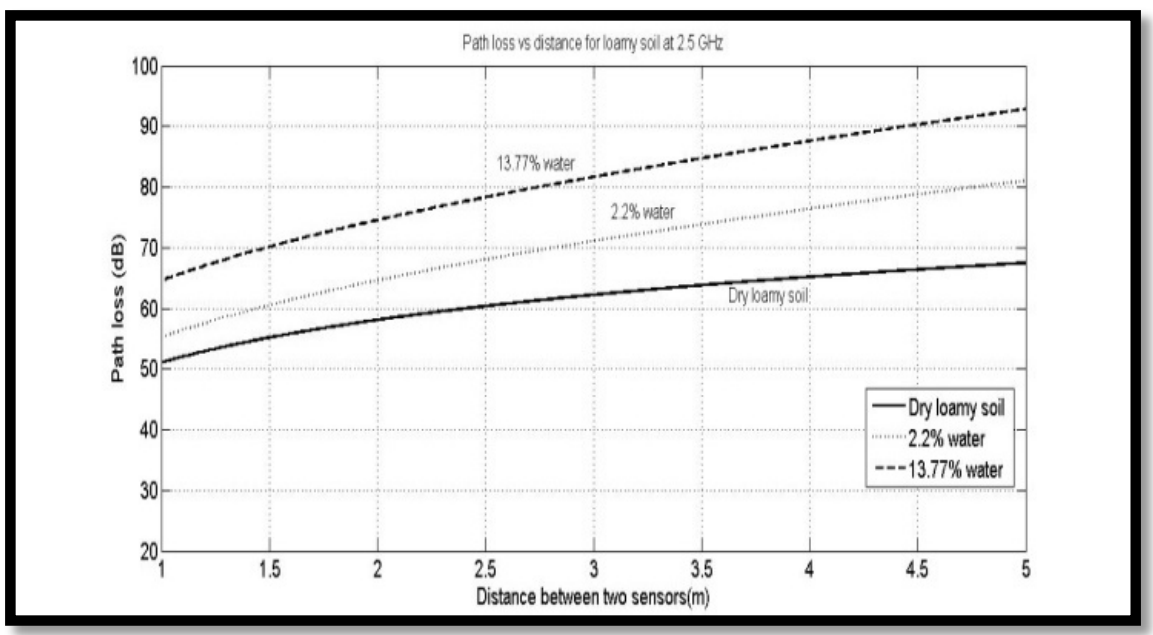

Figure 5. Path loss $(\mathrm{dB})$ as a function of distance between two sensors $(\mathrm{m})$ at frequency $2.5 \mathrm{GHz}$ for loamy soil at different water concentrat ion 


\subsubsection{Loamy Soil}

The Bulk density of the Loamy soil is $1.4 \mathrm{~g} / \mathrm{cm}^{3}$ and the pore space is $47 \%$ which means the Loamy soil become finer in texture[29].

The loamy soils with three different concentrations of water are introduced in this section. The path loss for the dry loamy soil with relative permittivity $\varepsilon{ }^{\prime}=2.44$ and tangent loss is $\tan (\delta)=0.0011$, loamy soil $2.2 \%$ water with $\varepsilon^{\prime}=3.5$ and $\tan (\delta)=0.04$ and loamy soil $13.77 \%$ water with $\varepsilon^{\prime}=20$ and $\tan (\delta)=0.12$ at $2.5 \mathrm{GHz}$ are introduced.

The frequency as a function on the path loss for different water concentration for loamy soil at distance $1 \mathrm{~m}$ separation between sensors is illustrated in Figure 4. Increasing water concentration leads to increasing path loss. In Figure 5, the effect of distance on a path loss is illustrated at frequencies $2.5 \mathrm{GHz}$ for loamy soil.

\subsubsection{Magnetite So il}

A sandy soil with a large amount of heavy minerals such as magnetite is called a magnetite soil. The particle density is getting higher for magnetite soil[30]. The magnetite soil is a pure soil contains iron oxide particles[31].

The magnetite soils with three different concentration of water are introduced in this section. The path loss for the dry magnetite soil with relative permittivity $\varepsilon^{\circ}=1.05$ and tangent loss is $\tan (\delta)=0.029$, magnetite soil $4.8 \%$ water with $\varepsilon^{`}=8.3$ and $\tan (\delta)=0.22$ and magnetite soil $11 \%$ water with $\varepsilon^{\prime}=30$ and $\tan (\delta)=0.32$ at $2.5 \mathrm{GHz}$ are introduced.

The frequency as a function on the path loss for different water concentration for magnetite soil at distance $1 \mathrm{~m}$ separation between sensors is illustrated in Figure 6 . Increasing water concentration leads to increasing path loss. In Figure 7, the effect of distance on a path loss is illustrated at frequencies $2.5 \mathrm{GHz}$ for magnetite soil.

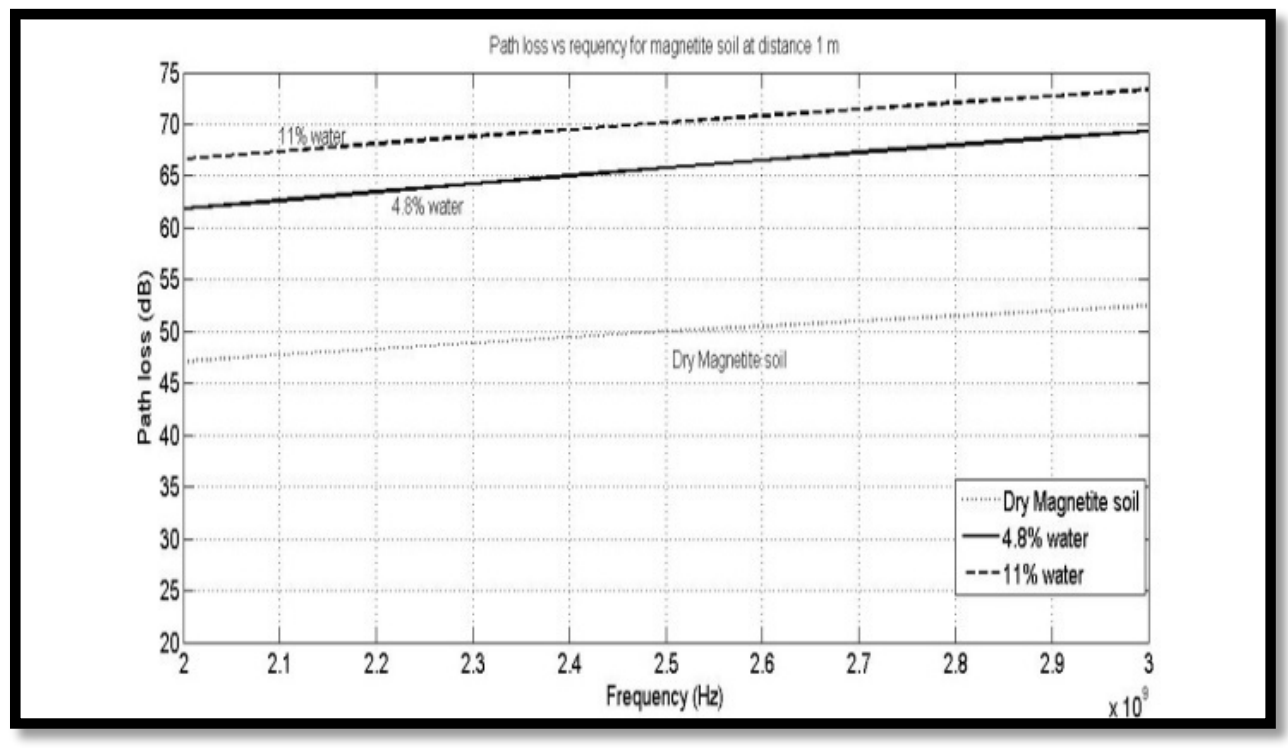

Figure 6. Path $\operatorname{loss}(\mathrm{dB})$ as a function of frequency $(\mathrm{GHz})$ for magnet ite soil at different water concentration at distance $1 \mathrm{~m}$

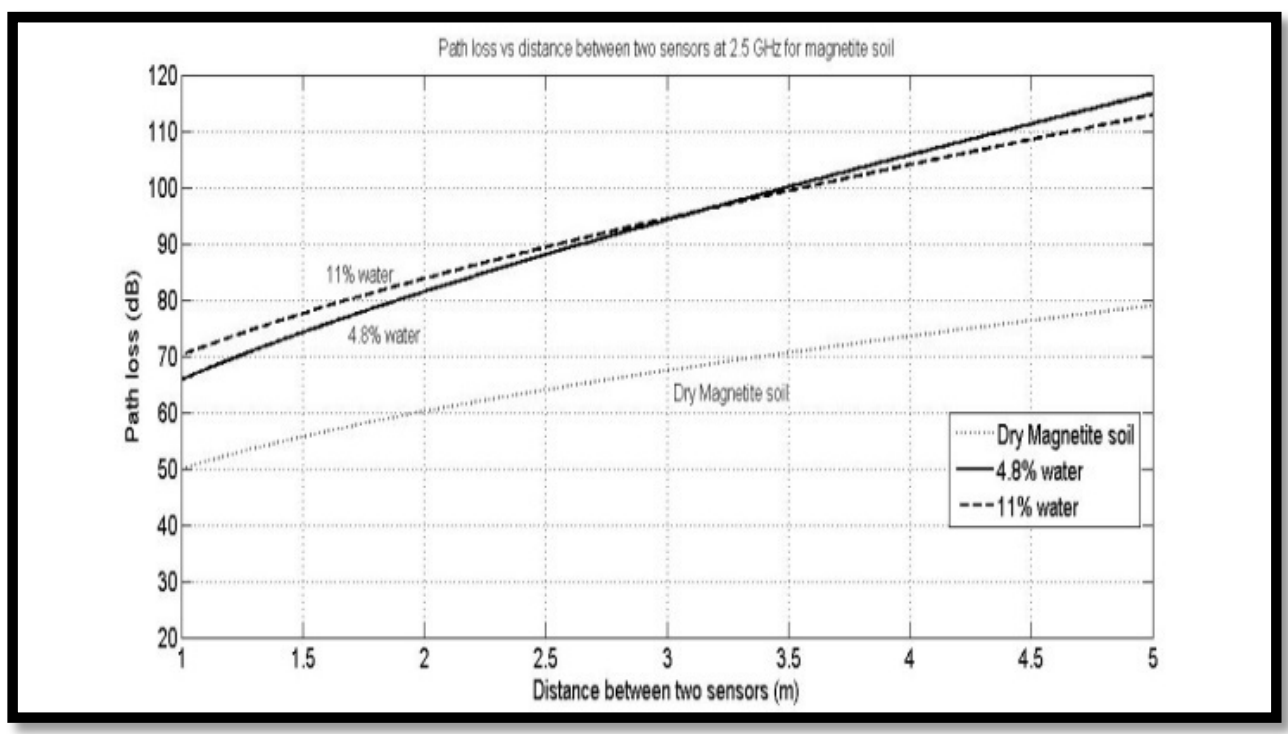

Figure 7. Path loss $(\mathrm{dB})$ as a function of distance between two sensors $(\mathrm{m})$ at frequency $2.5 \mathrm{GHz}$ for magnetite soil at different water concentration 


\subsection{Reflection Calculation}

An extra loss due to reflection is obtained. The reflection from soil air interface is studied in this section. Some approximations are assumed here to simplify the simulation as in Figure 1 as follows:

- The sensors are in the middle of the sand height, $H_{1}=$ $\mathrm{H}_{2}=\mathrm{H}$.

- All multipath are equal, $r_{1}=r_{2}=r$.

- Distances $d_{1}=d_{2}=d$.

The path loss due to reflection from soil surface interface is calculated as a function of sensor depth $\mathrm{H}$ at distance between sensors $1 \mathrm{~m}$ and $2.5 \mathrm{GHz}$ frequency for three different soils. As shown in Figure 8, the effect of water concentration on the reflection loss is very high for the dry soil. As the water concentration and sensor depth increased, the path loss decreased to be negligible at depth $5 \mathrm{~m}$. The same conclusion is obtained in Figure 9. Path loss due to reflection as a function of depth at $2.5 \mathrm{GHz}$ and distance $1 \mathrm{~m}$ is illustrated in Figure 9 for loamy soil. Reflection for magnetite soil at different water concentration after $3 \mathrm{~m}$ depth is almost vanishing as shown in Figure 10.

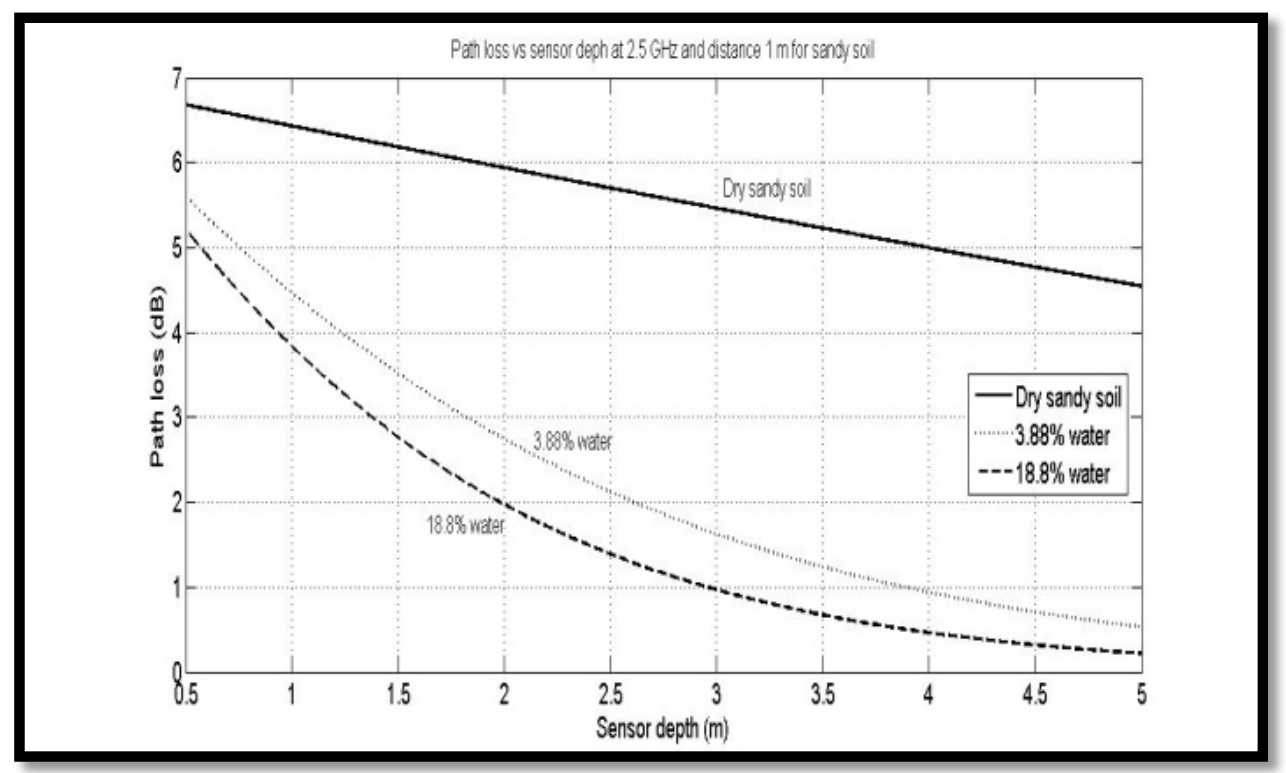

Figure 8. Path loss $(\mathrm{dB})$ as a function of sensor depth $(\mathrm{m})$ at frequency $2.5 \mathrm{GHz}$ and distance between two sensors $1 \mathrm{~m}$ for sandy soil at different water concentration

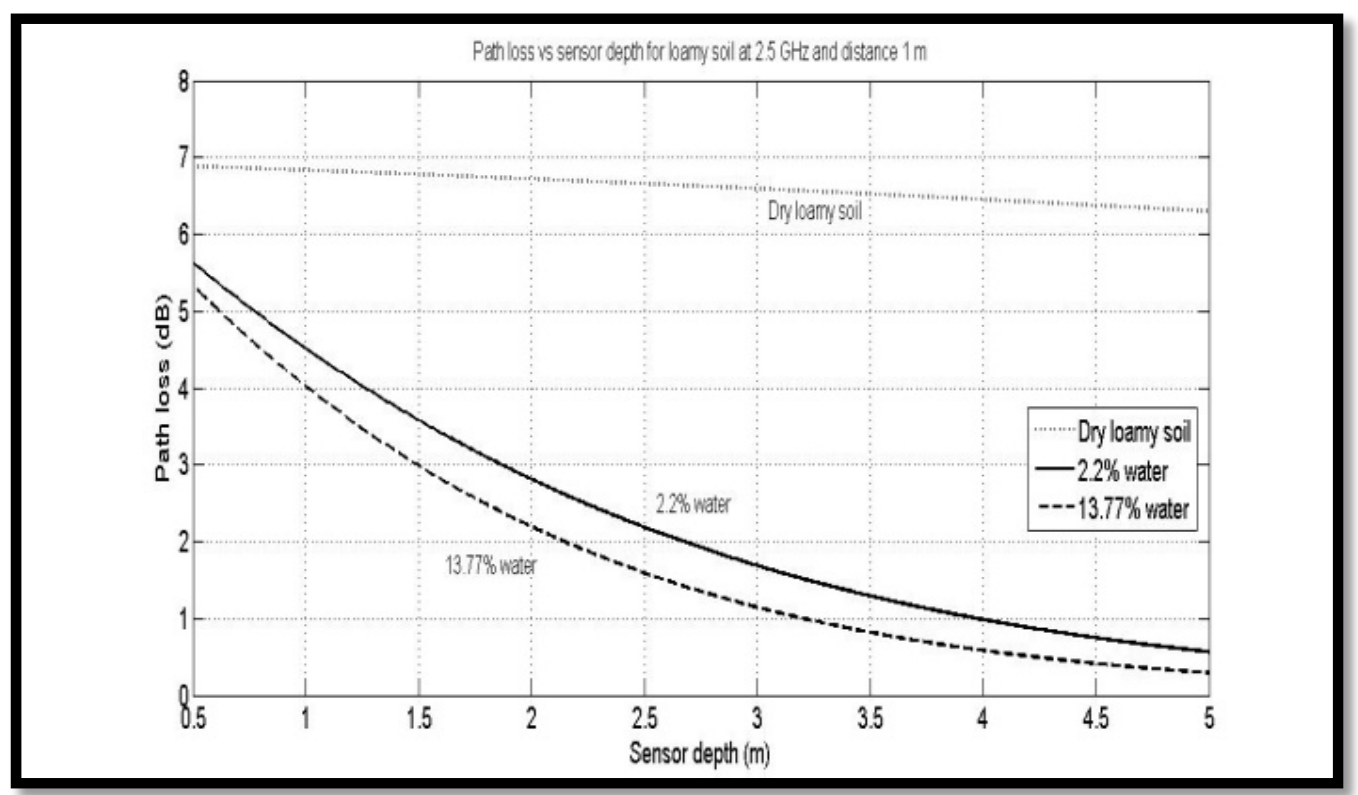

Figure 9. Path loss $(\mathrm{dB})$ as a function of sensor depth $(\mathrm{m})$ at frequency $2.5 \mathrm{GHz}$ and distance between two sensors $1 \mathrm{~m}$ for loamy soil 


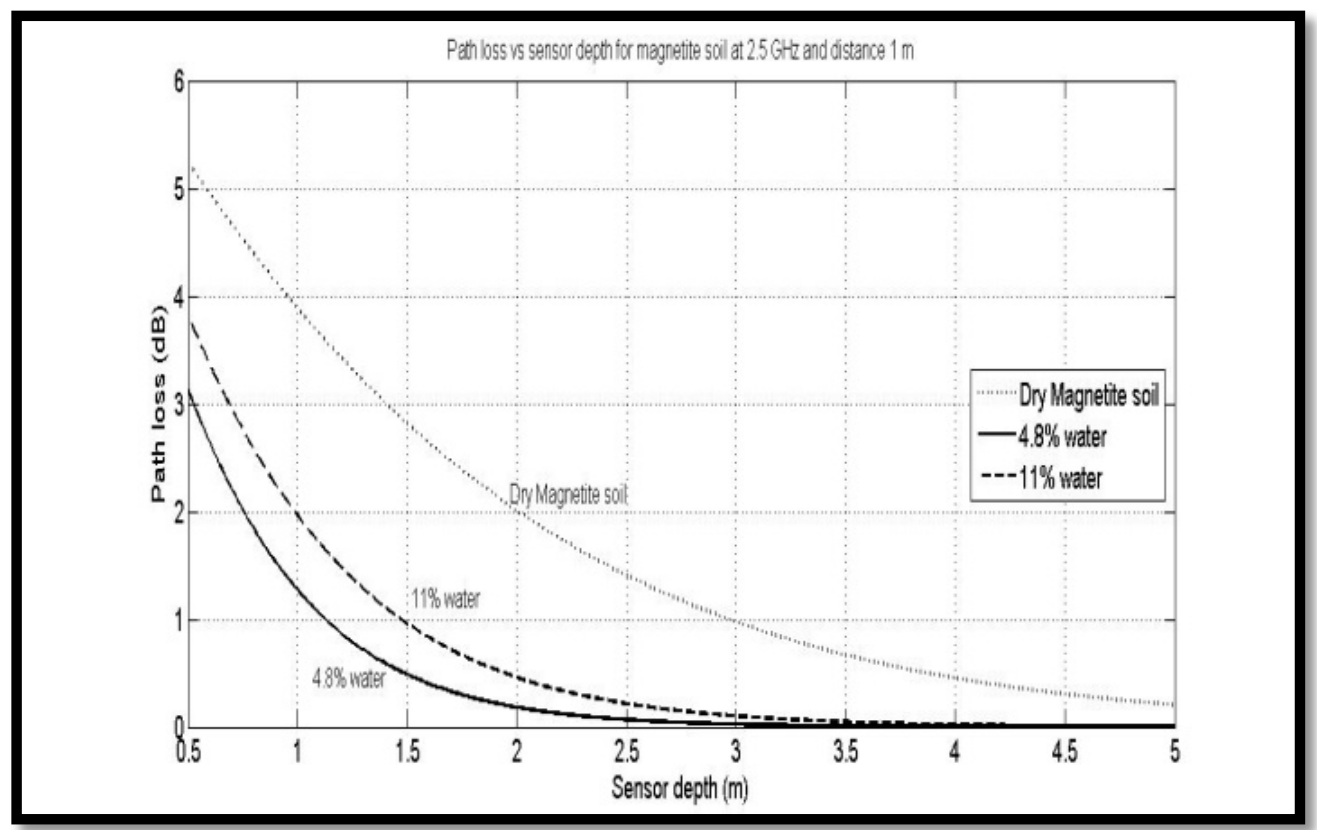

Figure 10. Path loss $(\mathrm{dB})$ as a function of sensor depth $(\mathrm{m})$ at frequency $2.5 \mathrm{GHz}$ and distance between two sensors $1 \mathrm{~m}$ for magnet ite soil at different water concentration

\subsection{Antenna Design}

Circular microstrip antenna operates at $2.5 \mathrm{GHz}$ design is shown in Figure 11. FEKO software is used to design and simulate this antenna. The dimensions of the designed antenna are as follow: antenna patch diameter is $30.36 \mathrm{~mm}$, substrate height is $1.5 \mathrm{~mm}$, substrate length is $75.9 \mathrm{~mm}$, substrate width is $75.9 \mathrm{~mm}$ and the dielectric constant is 4.35.

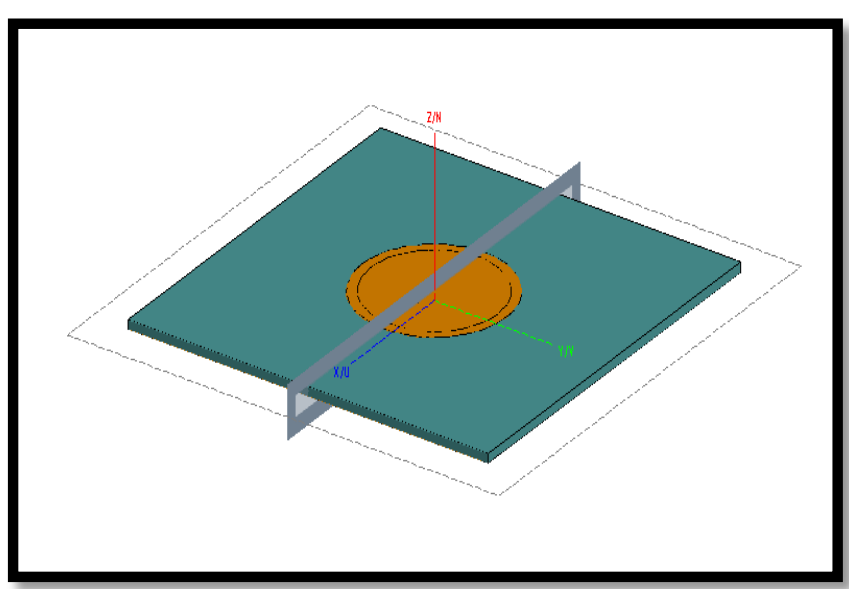

Figure 11. Designed circular microstrip antenna operates at $2.5 \mathrm{GHz}$

Figure 12 shows the radiation pattern in $\mathrm{dB}$ of the microstrip circular antenna operates at $2.5 \mathrm{GHz}$. The radiation pattern is concentrated in the upper face of the antenna. The return loss is shown in Figure 13. Return loss value is $-25 \mathrm{~dB}$ at $2.5 \mathrm{GHz}$ wh ich is very efficient for using in underground use, should be less than $-10 \mathrm{~dB}$ in most of underground applications. Figure 14 shows the voltage standing wave ratio for the designed antenna.

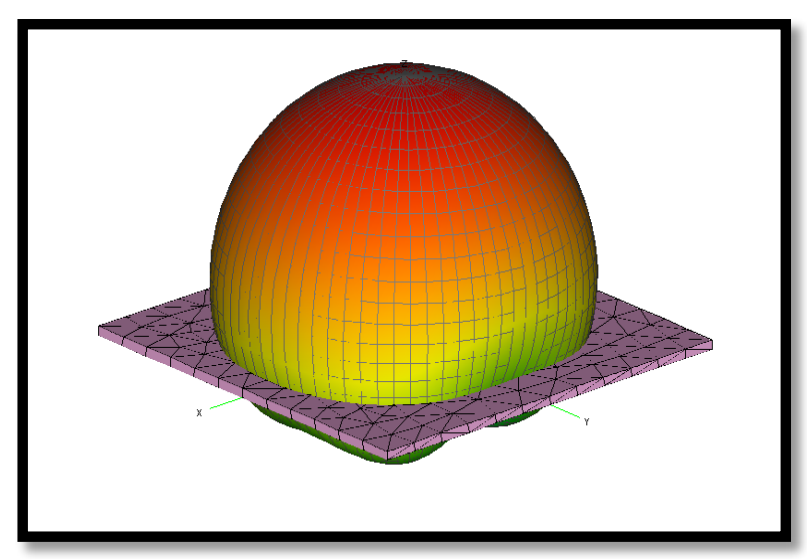

Figure 12. Radiation pattern of microstrip circular $(\mathrm{dB})$ antenna operates at $2.5 \mathrm{GHz}$

The VSWR value is 1.1 at $2.5 \mathrm{GHz}$ which is very efficient in manufacture process of the microstrip circular antenna. Real part of input impedance is shown in Figure 15; the real value of input impedance is almost $50 \mathrm{ohm}$ at $2.5 \mathrm{GHz}$ which match the transmission line impedance. The maximum gain is obtained at $2.5 \mathrm{GHz}$ at the radiation angle 00 for the designed antenna as shown in Figure 15. 


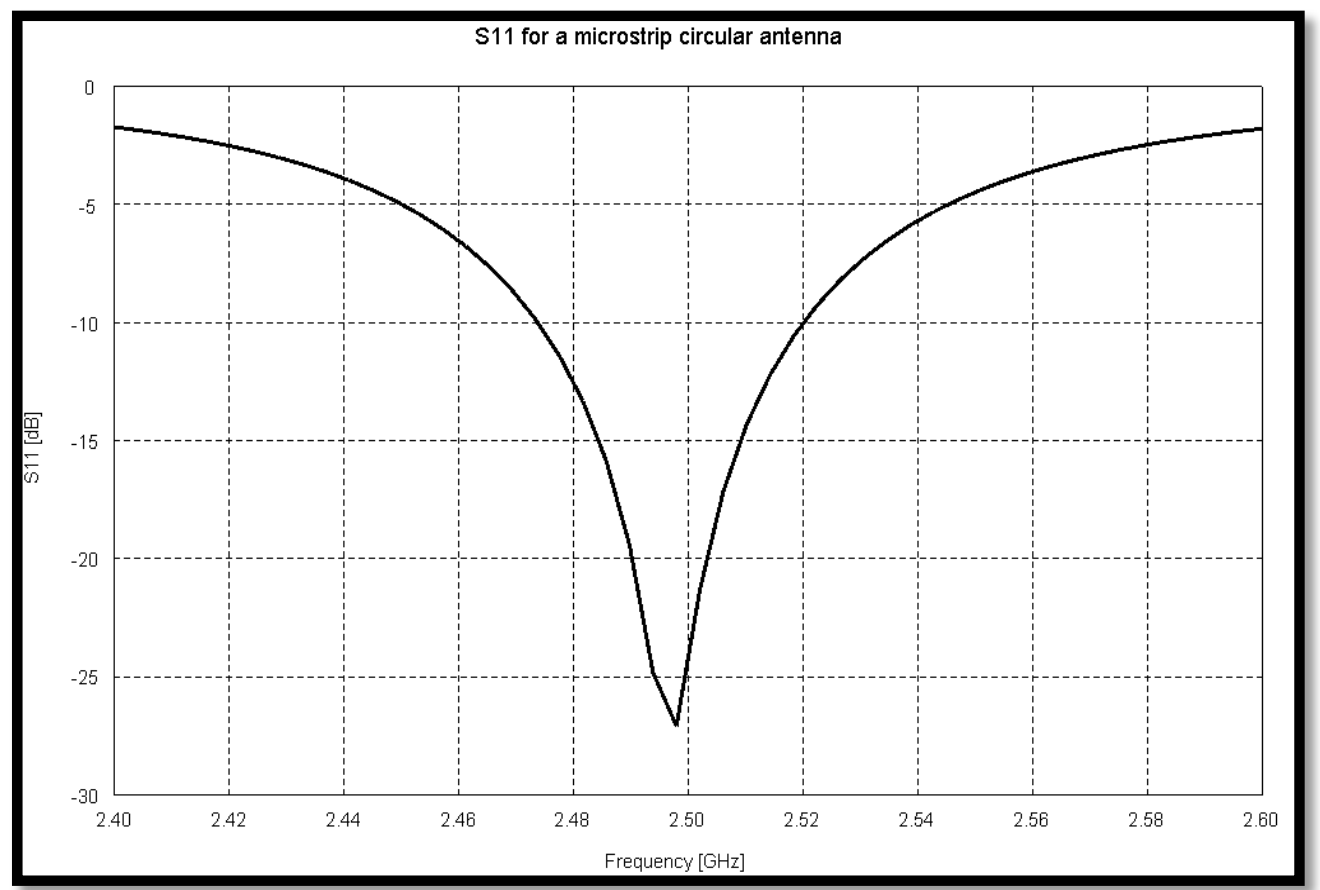

Figure 13. Return loss ( $\mathrm{S} 11)$ as a function of frequency $(\mathrm{GHz})$

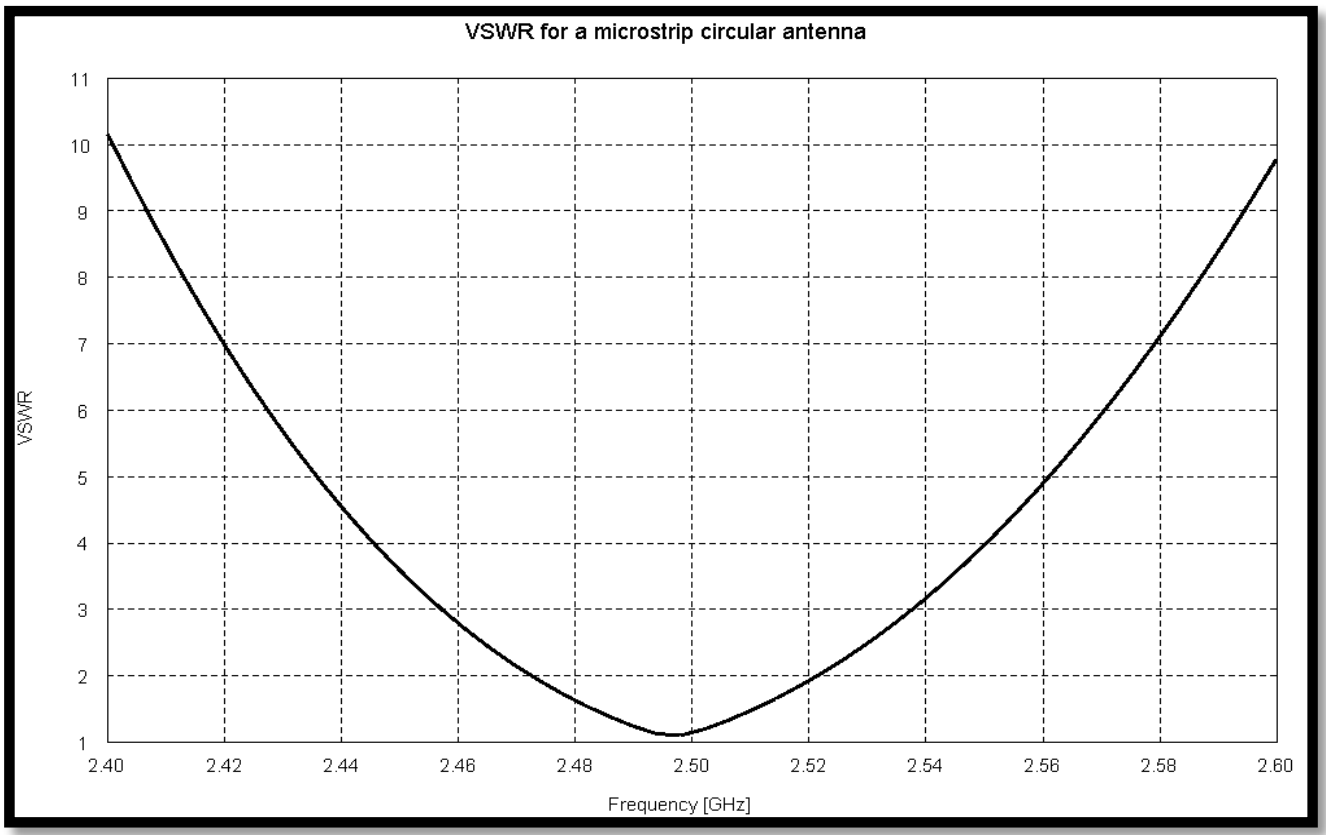

Figure 14. Voltage standing wave ratio as a function of frequency $(\mathrm{GHz})$ 


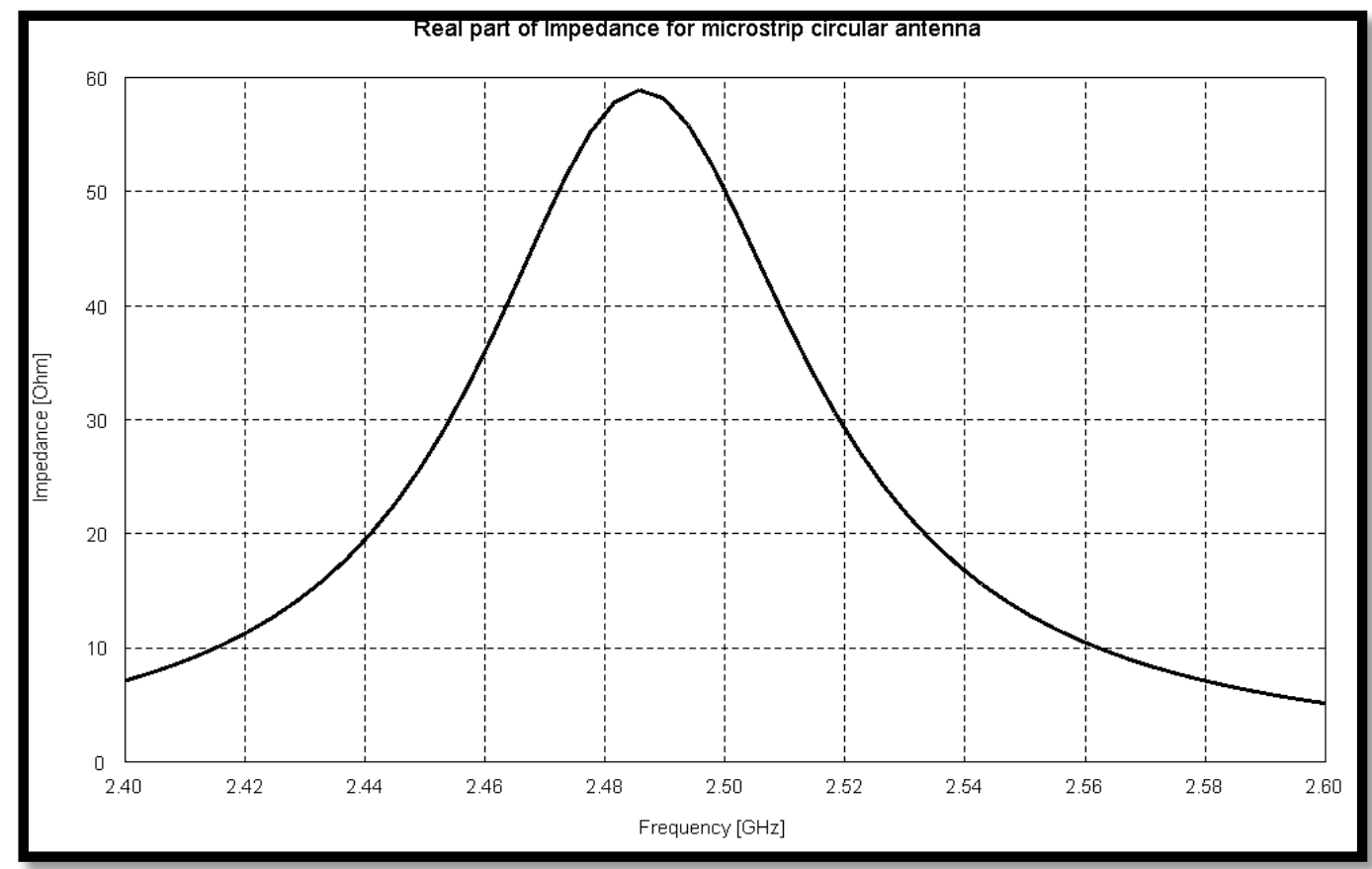

Figure 15. Input impedance as a function of frequency $(\mathrm{GHz})$

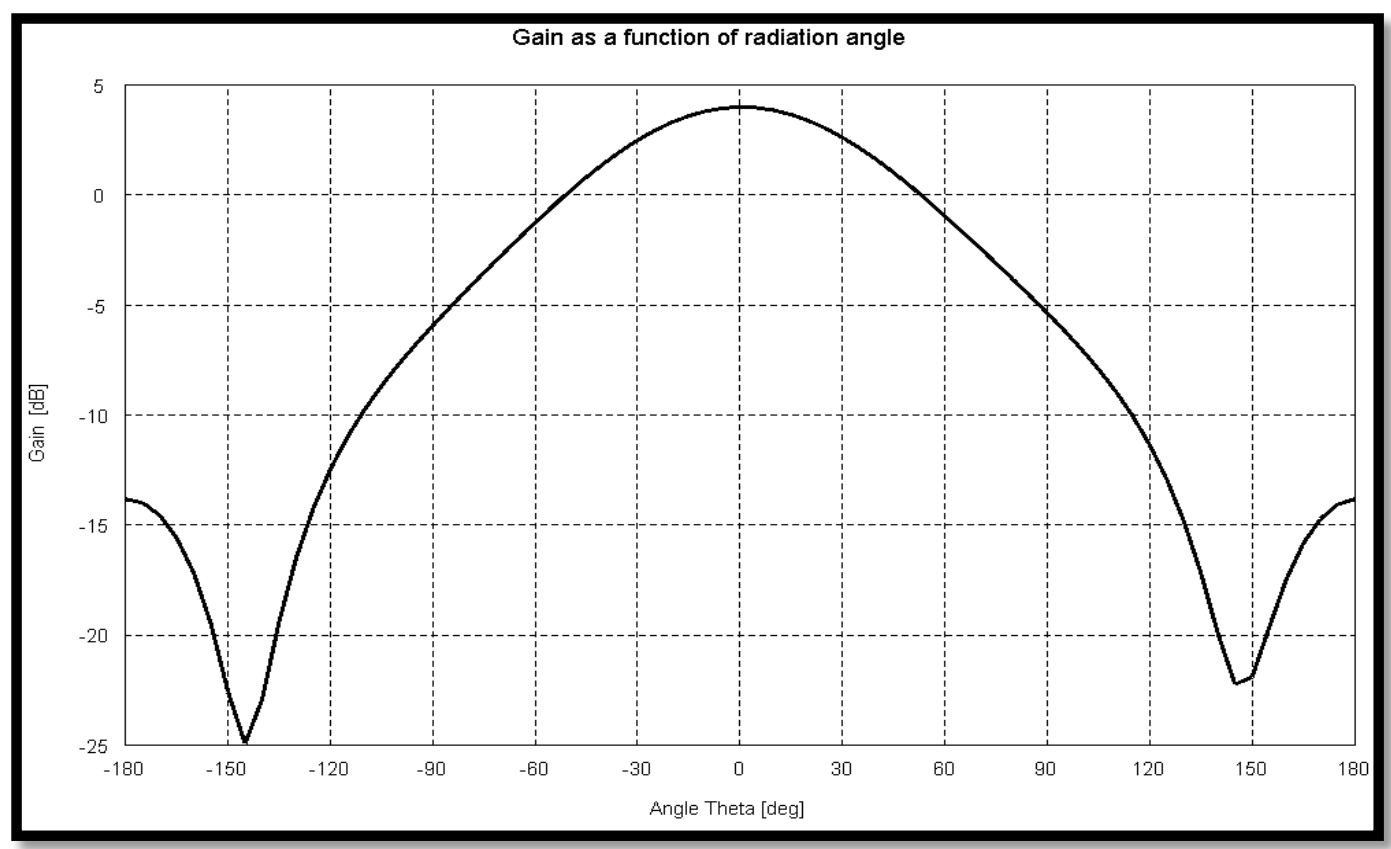

Figure 16. Antenna gain as a function of radiation angle at $2.5 \mathrm{GHz}$

\section{Conclusions}

A mathematical model for path loss due to attenuation of electromagnetic waves propagates in different types of soil resonates at $2.5 \mathrm{GHz}$ is introduced in this paper. The reflection of electro magnetic waves at the air-soil interface is given as a function of sensor depth in soil and distance between sensors. Three different types of soil are given in this paper, sandy, loamy and magnetite soil. For lower permittivity, the path loss is a low value. The higher distance between sensors leads to higher losses is produced.
The reflection from air-soil interface is negligible in case of deep soil, after $3 \mathrm{~m}$, except for dry sandy soil and dry loamy soil.

A high gain microstrip circular antenna is designed and simulated using FEKO software. Return loss, voltage standing wave ratio, real part of input impedance and gain is also given in this paper. S1 1 of the designed antenna is -25 $\mathrm{dB}$ at $2.5 \mathrm{GHz}$, which is very efficient value for underground wireless communication to overcome the high path loss due attenuation. 


\section{REFERENCES}

[1] W. Dargie and C. Poellabauer, "Fundamentals of Wireless Sensor Networks: Theory and Practice," John Wiley and Sons, 2010.

[2] K. Hunt, J. Niemeier and A. Kruger, "RF Communications in Underwater Wireless Sensor Networks," IEEE International Conference on Electro/Information Technology (EIT), pp. 1-6, Oct., 2010.

[3] J. Tiusanen, "Attenuation of a Soil Scout Radio Signal," Biosy stems Eng., vol. 90, no. 2, pp. 127-133, Feb. 2005.

[4] J. Tiusanen, "Validation and Results of the Soil Scout Radio Signal Attenuation Model," Biosystems Eng., vol. 97, no. 1, pp. 11-17, May 2007.

[5] J. Tiusanen, "Wireless Soil Scout Prototype Radio Signal Reception Compared to the Attenuation Model," Precis. Agric., vol. 10, no. 5, pp. 372-381, Oct. 2009.

[6] I. Akyidiz "A Mode-Based Approach for Channel Modeling in Underground Tunnels under the Impact of Vehicular Traffic Flow," IEEE Trans. on Wireless Communication, vol. 10, no. 10, pp. 3222-3231, Oct. 2011.

[7] E. Stuntebeck, D. Pompili and T. Melodia, "Wireless Underground Sensor Networks Using Commodity Terrestrial Motes," 2nd IEEE Workshop on Wireless Mesh Networks, Reston, pp. 112-114, 2006.

[8] J. Huang, R. Kumar, A. Kumar and R. Weber, "Development of a Wireless Soil Sensor Network," ASABE International meeting, Providence, Paper 080025, 2008.

[9] N. Chaamwe, W. Liu and H. Jiang, "Wave Propagation Communication Models for Wireless Underground Sensor Networks" 12th IEEE International Conference on Communication Technology (ICCT), pp. 9-12, Nov. 2010.

[10] I. Akyildiz, Z. Sun and M. Vuran, "Signal Propagation Techniques for Wireless Underground Communication Networks" Physical Communication, vol. 2, pp. 167-183, Sep. 2009.

[11] I. Akyildiz and E. Stuntebeck, "Wireless Underground Sensor Networks: Research Challenges" Ad Hoc Networks (Elsevier), vol. 4, no. 6, pp. 669-686, Nov. 2006.

[12] X. Che, I. Wells, P. Kear, G. Dickers, X. Gong and M. Rhodes, "A Static Multi-hop Underwater Wireless Sensor Network Using RF Electromagnetic Communications," 29th IEEE International Conference on Distributed Computing Systems Workshops, Montreal, Canada, pp. 460-463, 2009.

[13] R. Von, "Dielectric Materials and Applications" M.I.T press, Cambridge, MA, 1954.

[14] M. Rhodes, "Electromagnetic Propagation in Seawater and its Value in Military Systems," SEAS DTC Technical Conference, Edinburg, UK, 2007.

[15] N. Peplinski, F. Ulaby and M. Dobson, "Dielectric Properties of Soils in the $0.3-1.3 \mathrm{GHz}$ range" IEEE Transaction on Geosciences and Remote Sensing vol. 33, no. 3, pp. 803-807, 1995.
[16] I. Akyildiz and Z. Sun "On capacity of magnetic induction-based wireless underground sensor networks", IEEE INFOCOM, 2012 Proceedings, pp. 370 - 378, March 2010.

[17] T. Weldon and Y. Rathore, "Wave Propagation Model and Simulation for Landmine Detection" Tech. rep., University of N. Carolina at Charlotte, 1999.

[18] T. Miller, B. Bochers, J. Hendrickx, S. Hong, L. Dekker and C. Ritsema, "Effect of Soil Physical Properties on GPR for Landmine Detection" 5th International Symposium on Technology and the Mine Problem, 2002.

[19] R. Musaloiu, A. Terzis, A. Szalay, J. Cogan and J. Gray, "Life Under Your Feet: A Wireless Soil Ecology Sensor Network" EmNet'06, Pro. of the 3rd IEEE Con. On Embeded Networked Sensors, 2006.

[20] L. Jui-Han, "Bandwidth enhancement design of single-layer slotted circular microstrip antennas" IEEE Transactions on Antennas and Propagation, vol. 51, Issue 5, pp. 1126-1129, May 2003.

[21] P. Zade, S. Khade and N. Choudhary, "Modeling and Designing of Circular Microstrip Antenna for Wireless Communication" 2nd International Conference on Emerging Trends in Engineering and Technology (ICETET), pp. 1189-1194, Dec. 2009

[22] N. Zakaria, A. Sulaiman and M. Latip, "Design of a circular microstrip antenna" IEEE International RF and Microwave Conference, pp. 289-292, Dec. 2008.

[23] C. Sim, L. Kuang-Woei and R. Jeen-Sheen, "Design of an annular-ring microstrip antenna for circular polarization" IEEE Antennas and Propagation Society International Symposium, vol. 1, pp. 471-474, June 2004.

[24] G. Stuber, "Principles of Mobile Communication," Klumer Academic Publishers, 1996, 2001.

[25] S. Ramo, J. Whinn ery and T. Van Duzer, Fields and Water for Communications Electronics, John Wiley and Son, New York, 1994.

[26] J. Wait, Electromagnetic Wave Theory, Harper and Row, New York, 1985.

[27] D. Cheng, "Field and Wave Electromagnetics," Addison Wesley Publisher, 2nd edition, Jan., 1989.

[28] P. Birkeland, Soils and Geomorphology: Oxford University Press, New York, 1984.

[29] G. Blake and K. Hartge, Bulk Density, in A. Klute, ed., Methods of Soil Analysis, Part I. Phy sical and Mineralogical Methods: Agronomy Monograph no. 9 (2nd ed.), 1986.

[30] B. Brasher, D. Franzmeier, V. Valassis, and S. Davidson, Use of saran resin to coat natural soil clods for bulk density and moisture retention measurements: Soil Science v. 101, p. 108, 1966.

[31] A. Tisdall, Comparison of methods of determining apparent density of soils, Australian Journal of A gricultural Research, v. 2, pp. 349-354, 1951. 